\title{
UNA NUEVA ESPECIE DE CAREX (CYPERACEAE) DE QUERETARO
}

\author{
SOCORRO Gonzalez Elizondo \\ CIIDIR y COFAA Instituto Politécnico Nacional \\ Apdo. postal 738 \\ 34000 Durango, Durango, México \\ Y \\ Anton A. ReZnicek \\ University of Michigan Herbarium \\ North University Building \\ Ann Arbor, MI 48109 E.U.A.
}

\section{RESUMEN}

Se describe Carex evadens sp. nov., una planta escasa del estado de Querétaro. Esta especie está relacionada con Carex fructus Reznicek y C. distentiformis F. J. Herm. De la primera difiere principalmente en tener periginios y aquenios más anchos, y de la segunda en sus espigas inferiores simples y los periginios de color verde pálido, no café-rojizo. Se presenta una clave para separar las tres especies.

\section{ABSTRACT}

Carex evadens sp. nov., a scarce species known from the Mexican state of Queretaro, is described. It is related to $C$. fructus Reznicek and to $C$. distentiformis F. J. Herm., differing from the first mainly in having wider perigynia and achenes and from the second in the simple lower spikes and pale green, not reddish brown perigynia. A key to separate these species is given.

Carex evadens S. González \& Reznicek sp. nov. Fig. 1.

Plantae cespitosae, rhizoma lignosum; culmi fertiles $16-70 \mathrm{~cm}$ alti; vaginis basalibus glabris, brunneis vel purpureis. Folia 4-7(-10), laminae 12-60 cm longae, 5-7.9 mm latae; vaginae glabrae, ventraliter albido-hyalinae vel pallido stramineae; ligulae truncatae vel acutae usque ad $10 \mathrm{~mm}$ longae. Inflorescentiae $7.5-38 \mathrm{~cm}$ longae, spicae $5-7$, supernae 1-3 staminatae; bracteae infimae laminis usque ad $37 \mathrm{~cm}$ longis, 3.1-6 mm latis; spica terminalis omnino staminata, usque ad $4.7 \mathrm{~cm}$ longa, 3.1-4.5 mm lata, subsessilis vel pedunculata; spicae laterales pistillatae 4-5, 1.9-4.6 cm longae, 7-10 mm latae, floribus 60-105 imbricatibus. Squamae pistillatae corpibus $1.9-2.4(-2.9) \mathrm{mm}$ longis, $0.9-2 \mathrm{~mm}$ latis, acuminatis, obtusis vel emarginatis, aristatis, aristae 0.2-1.6 mm longae. Perigynia (3.4-)3.8-4.6 mm longa, (1.3-)1.5-1.8 mm lata, patula, extrorsus curvata, glabra, viridia, 
corporibus obtuse trigonis vel biconvexis, in rostrum 1-1.4(-1.7) mm longum contracta. Achenia 2.1-2.9 mm longa, 1.1-1.5 mm lata, trigona. Styli marcescentes; stigmata 3. Antherae 2.6-2.8 mm longae.

Planta cespitosa, con rizoma fuerte y robusto; raíces cubiertas con pubescencia aterciopelada o pronto glabras; tallos fértiles de 16-70 $\mathrm{cm}$ de altura, de sección triangular, lisos, cubiertos en el extremo proximal por las bases persistentes y algo fibrosas de las vainas foliares inferiores y por vainas basales no foliares glabras, de color café o teñidas de rojo-púrpura. Hojas 4-7(-10), en su mayoría basales; láminas $12-60 \mathrm{~cm}$ de longitud, 5-7.9 mm de anchura, planas, glabras, diminutamente papilosas en el envés, los márgenes y la nervadura central escabrosos distalmente; vainas foliares glabras, de color verde pálido o pajizo, ventralmente hialinas cuando jóvenes, blanco-hialinas o pajizas al madurar, el ápice de las vainas inferiores truncado o débilmente prolongado en una contralígula hasta de $1.5 \mathrm{~mm}$ de longitud; lígula truncada, convexa, o bien, en las hojas superiores, aguda y hasta de $10 \mathrm{~mm}$ de longitud, con la porción libre entera, ondulada, de color café a rojizo, 0.4-1.4 mm de longitud. Vástagos vegetativos $10-50 \mathrm{~cm}$ de altura, con 4-8 hojas similares a las de los tallos fértiles; pseudotallos hasta de $12 \mathrm{~cm}$ de altura. Inflorescencias 7.5-38 cm de longitud, 2-3.6 cm de ancho, con 5-7 espigas; espiga terminal estaminada, a veces con 2 espigas estaminadas reducidas asociadas; espigas laterales pistiladas (¿a veces andróginas?), las espigas laterales superiores más o menos agrupadas, y las 1 ó 2 inferiores distantes $4-17 \mathrm{~cm}$, sobre pedúnculos filiformes, escabrosos o casi lisos, (1.6-)3.7-5.2 cm de longitud; espigas solitarias en los nudos, erectas o ascendentes; brácteas inferiores foliáceas, hasta de $37 \mathrm{~cm}$ de longitud, 3.1-6 mm de anchura, antrorsamente escabrosas sobre los márgenes y la nervadura central, con vainas hasta de $9 \mathrm{~cm}$ de longitud, las brácteas superiores setáceas, muy reducidas. Espiga terminal hasta de $4.7 \mathrm{~cm}$ de longitud, 3.1-4.5 $\mathrm{mm}$ de anchura, casi sésil o sobre un pedúnculo de 5-7 mm de longitud; espigas laterales estaminadas, de estar presentes, $0.5-1.2 \mathrm{~cm}$ de longitud, $0.2-0.3 \mathrm{~cm}$ de anchura, sésiles o sobre un pedúnculo hasta de $3 \mathrm{~mm}$ de longitud; espigas laterales pistiladas 1.9-4.6 cm de longitud, 7-10 mm de anchura, con 60-105 periginios. Glumas pistiladas (cuerpo) 1.9-2.4(-2.9) $\mathrm{mm}$ de longitud, 0.9-2 $\mathrm{mm}$ de anchura, ovadas a oblongas, glabras, de color pajizo, con frecuencia teñidas de púrpura-rojizo, con el centro trinervado de color verde, acuminadas, obtusas o emarginadas, la nervadura central usualmente prolongada en una arista de 0.2-1.6 mm de longitud; glumas estaminadas 3-4.8 $\mathrm{mm}$ de longitud, 0.8-1.2 $\mathrm{mm}$ de anchura, estrechamente oblongas, glabras, de color pajizo a café pálido o rojizo, con el centro trinervado de color verde a pajizo y los márgenes hialinos, emarginadas o a veces agudas a acuminadas, usualmente prolongadas en una arista hasta de $0.5 \mathrm{~mm}$ de longitud. Periginios (3.4-)3.8-4.6 mm de longitud, (1.3-)1.5-1.8 mm de anchura, patentes, curvados hacia afuera, de sección obtusamente triangular o algo biconvexos, los lados convexos, ovados, glabros, de color verde, tenuemente punteados de rojo en la madurez, con 12-18 nervaduras, las dos laterales más prominentes, sésiles, con el ápice gradual o abruptamente estrechado en un pico; picos 1-1.4(-1.7) mm de longitud, lisos o muy levemente escabrosos sobre los márgenes, bidentados con dientes delgados de 0.3-0.5 mm de longitud. Aquenios 2.1-2.9 mm de longitud, 1.1-1.5 mm de anchura, de sección triangular con los lados planos a débilmente convexos, elípticos a oblongos, estrechados hacia la base y el ápice, diminutamente 


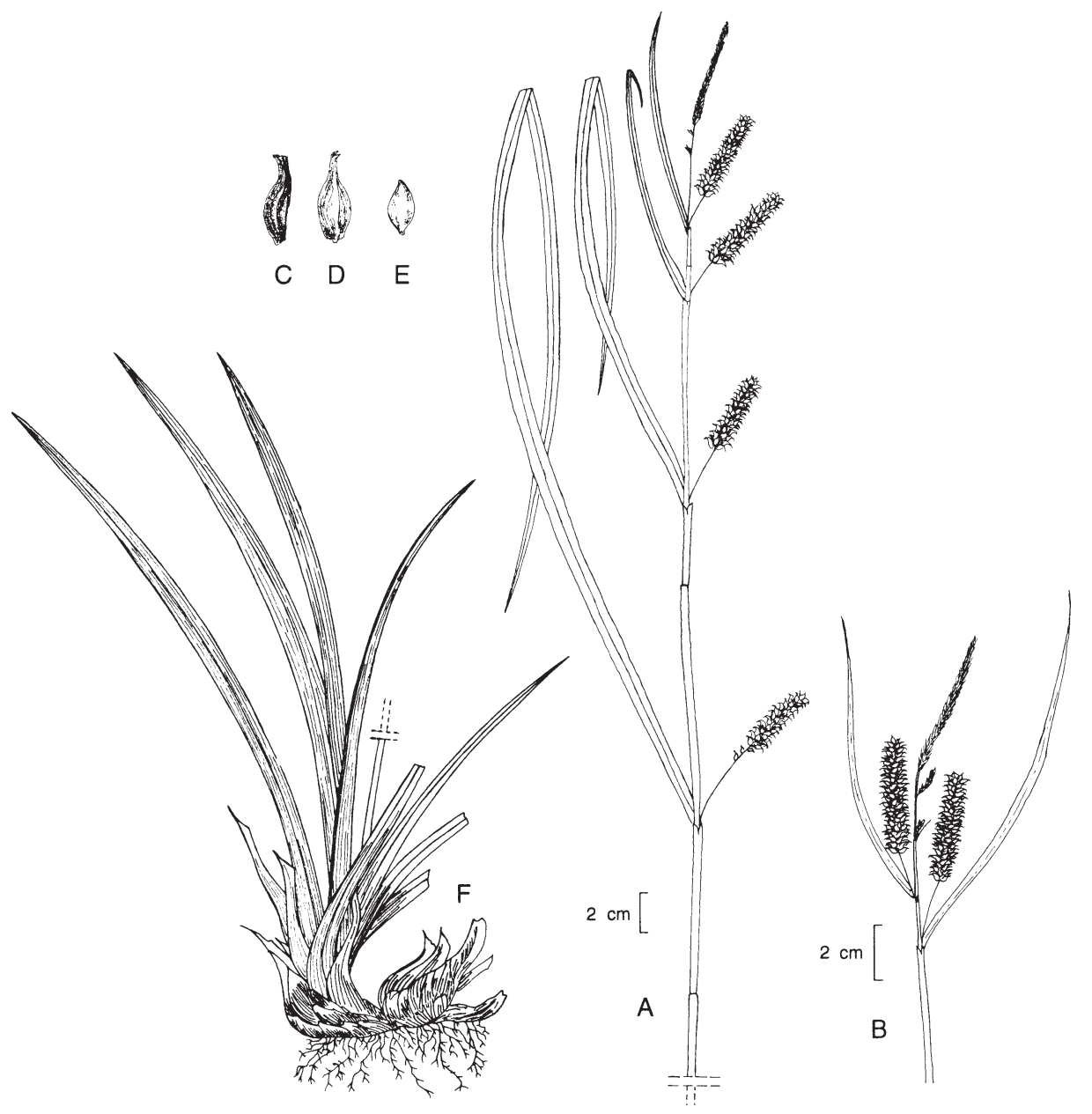

Fig. 1. Carex evadens S. González \& Reznicek. A. Inflorescencia. B. Porción superior de la inflorescencia. C. Periginio, vista lateral. D. Periginio, vista frontal. E. Aquenio, vista frontal. F. Parte basal de la planta. 
vesiculares, de color amarillento a café, sésiles o cortamente estipitados, no o muy cortamente apiculados. Estilo curvado, tempranamente deciduo; estigmas 3. Anteras 3(?), 2.6-2.8 $\mathrm{mm}$ de longitud.

TIPO: México, Querétaro, 3-4 km al S de La Parada, El Pilón, municipio de Jalpan, bosque de pino y encino, 1400-1500 m, 24.IV.1991, Benito Servín 994 (holotipo: IEB).

Material adicional examinado: México, Querétaro, $2 \mathrm{~km}$ al SO de Pinal de Amoles, ladera caliza con vegetación de bosque de P. patula, $2700 \mathrm{~m}, 24$.VI.1988, muy escasa, J. Rzedowski 46894 (IEB).

El espécimen colectado a $2700 \mathrm{~m}$ parece representar una forma reducida con inflorescencia compacta, la espiga estaminada inconspicua, y periginios y aquenios más pequeños.

Carex evadens está relacionada con Carex fructus Reznicek, conocida de Tamaulipas, y con C. distentiformis F. J. Herm., de Chiapas. Algunos de los caracteres que Reznicek (1990) puntualizó como comunes entre $C$. fructus y $C$. distentiformis, están también presentes en $C$. evadens, por ejemplo: espigas cilíndricas, con periginios patentes, curvados hacia afuera, banda interna de las vainas foliares inferiores prolongada en una língula o contralígula. De $C$. fructus, la especie aquí descrita difiere principalmente en tener hojas y brácteas de la inflorescencia más anchas, periginios más anchos, de color verde pálido en lugar de pajizos a cafés pálidos, aquenios más largos y más anchos, glumas estaminadas más estrechas, y anteras más largas. De C. distentiformis puede distinguirse por las espigas inferiores simples (vs. frecuentemente compuestas), exertas, por los periginios de color verde pálido, en lugar de rojizos o de color café obscuro, y por los periginios y glumas femeninas con tenue puntuación roja en lugar de densamente punteados de gotas resinosas rojas a obscuramente purpúreas.

Carex distentiformis fue considerada por Hermann $(1971,1974)$ como parte de la sección Extensae (Fries) Mackenzie [secc. Spirostachyae (Drejer) L. Bailey]. La posición taxonómica de Carex fructus y C. distentiformis fue discutida por Reznicek (1990), quien puntualizó que los periginios patentes y curvados hacia afuera, que le dan a las espigas una apariencia escuarrosa, quizá justifiquen el reconocimiento de una sección independiente.

Las tres especies pueden distinguirse mediante la siguiente clave:

1 Periginios 0.9-1.3 mm de ancho; aquenios 1.5-2.1 mm de longitud, 0.8-1.2 mm de anchura; glumas de las flores pistiladas usualmente emarginadas; hojas 2.4-5.6 mm de anchura C. fructus

1 Periginios (1.3-)1.5-1.9 mm de anchura; aquenios 2-2.9 mm de longitud, 1.1-1.5 mm de anchura; glumas de las flores pistiladas usualmente agudas a acuminadas; hojas 5-11 $\mathrm{mm}$ de anchura.

2 Espigas inferiores frecuentemente compuestas, con 1-2 espigas secundarias basales no exertas más allá de sus vainas; periginios y glumas de las flores pistiladas de color café-rojizo con manchas resinosas de color rojo obscuro 
2 Espigas inferiores simples, bien exertas más allá de sus vainas; periginios de color verde pálido, finamente punteados de color rojo, a veces de color púrpura en la base; glumas de las flores pistiladas de color pajizo, teñidas o rayadas de púrpura-rojizo C. evadens

Carex evadens se asemeja también, por lo menos superficialmente, a $C$. rhynchoperigynium S. D. Jones \& Reznicek, de la sección Hymenochlaenae, planta más delicada que prospera en sitios húmedos y abiertos a orillas de cascada en el estado de Hidalgo. Ambas especies presentan individuos de más o menos el mismo tamaño y tienen espigas cilíndricas de aproximadamente la misma longitud, periginios de color verdoso con picos curvados hacia afuera, y hojas papilosas en el envés. Sin embargo, Carex evadens tiene las vainas prolongadas en una contralígula o língula, al igual que $C$. fructus y que C. distentiformis, y las espigas laterales son erectas o ascendentes, al igual que las de esas dos especies. En C. rhynchoperigynium el ápice de la vaina carece de contralígula, y las espigas laterales son nutantes. Más específicamente, Carex evadens difiere en varios detalles: tiene una espiga terminal (estaminada) más ancha que la de $C$. rhynchoperigynium (3.1-4.5 mm vs. 1.4-3 mm), espigas pistiladas más anchas (7-10 mm vs. $3.5-7.5 \mathrm{~mm})$, aquenios más largos (2.1-2.9 mm vs. 1.8-2.1 mm), y anteras más largas (ca. 2.6-2.8 mm vs. $1.8-2.1 \mathrm{~mm}$ ).

\section{AGRADECIMIENTOS}

Damos las gracias al Dr. Jerzy Rzedowski por la búsqueda de duplicados de las dos colecciones de la especie descrita y por resolver dudas sobre la localidad del tipo. A los curadores de los herbarios ENCB, IEB, MEXU y MICH agradecemos las facilidades para consulta de material. S. González agradece al CONACyT por una beca para estudiar Carex en el herbario de la Universidad de Michigan.

\section{LITERATURA CITADA}

Hermann, F. J. 1971. New species of Carex from Mexico and Guatemala. Brittonia 23: 144-148.

Hermann, F. J. 1974. Manual of the genus Carex in Mexico and Central America. Agr. Handbook No. 467. Forest Service, U.S.D.A. Washington, D.C. 219 pp.

Reznicek, A. A. 1990. Four new species of Carex (Cyperaceae) from Mexico, with notes on the Mexican Carex flora. Contr. Univ. Mich. Herb. 17: 279-293. 